\title{
EFEITO DA RESTRIÇÃO ALIMENTAR QUANTITATIVA SOBRE O DESEMPENHO E AS CARACTERÍSTICAS DA CARCAÇA DE SUÍNOS EM TERMINAÇÃO
}

\section{MARSON BRUCK WARPECHOWSKI ${ }^{1}$; LUIZ MARIO FEDALTO ${ }^{1}$; ABEL RICIERI GUARESCHI NETO' ${ }^{2}$; SILVIA REGINA BEDIN ${ }^{3}$}

\author{
${ }^{1}$ Departamento de Zootecnia, Setor de Ciências Agrárias; ${ }^{2}$ Acadêmico Monitor da Disciplina de Suinocultura \\ do Curso de Medicina Veterinária; ${ }^{3}$ Bolsista do Programa Institucional de Bolsas de Iniciação Científica - \\ PIBIC - CNPq, Universidade Federal do Paraná.
}

\begin{abstract}
The effect of quantitative feed restriction upon the performance and carcass characteristics of the finished pigs was investigated. It was observed a linear reduction in the daily weight gain and backfat and linear increasing in the slaughtery age $(\mathrm{P}<0,05)$. The carcass weight and profit were affected in a quadratic way. Ham percentage showed linear increasing $(\mathrm{P}<0,05)$.
\end{abstract}

RESUMO - Neste experimento foi investigado o efeito da restrição alimentar quantitativa sobre o desempenho e a qualidade da carcaça de suínos em terminação. A restrição alimentar, na razão de 7 \% (T2), $14 \%$ (T3) e $21 \%$ (T4) do consumo à vontade (T1), diminuiu linearmente o ganho de peso diário e a espessura de toucinho, e aumentou linearmente a idade de abate $(\mathrm{P}<0,05)$, enquanto o peso e o rendimento de carcaça foram afetados de forma quadrática e a percentagem de pernil na carcaça aumentou linearmente conforme se diminuía a quantidade de ração fornecida $(\mathrm{P}<0,05)$.

\section{Introdução}

Os suínos apresentam maximização na velocidade de crescimento com dietas fornecidas à vontade, segundo formulações que atendam às exigências das diferentes fases do crescimento, como comprova o trabalho de LAWRENCE et al.
(1988). Entretanto, os níveis alimentares afetam a distribuição proporcional de gordura subcutânea e músculo, enquanto a razão músculo:osso não é afetada, de forma que carcaças de animais sob restrição devem apresentar proporcionalmente menor gordura e maior musculatura (GODFREY et al., 1991).

Tabela 1. Proporção de ingredientes e composição nutricional calculada para a dieta experimental.

\begin{tabular}{lc}
\hline \multicolumn{1}{c}{ Ingredientes } & Nível \\
\hline Milho & 75,19 \\
Farelo de Soja & 15,95 \\
Óleo & 0,81 \\
Lisina & 0,05 \\
Farelo de Trigo & 5,00 \\
Fosfato Bicálcico & 1,10 \\
Calcáreo & 1,00 \\
Sal Iodado & 0,40 \\
Premix vit. e min.* & 0,50 \\
\hline TOTAL & 100,00 \\
\hline Composição calculada & \\
\hline Proteína Bruta (\%) & 14,55 \\
Lisina (\%) & 0,70 \\
Energia Metabolizável (kcal/kg) & 3,300 \\
\hline *Nutris 0147 com antibiótico.
\end{tabular}

*Nutris 0147 com antibiótico.

A restrição alimentar pode incidir sobre a quantidade e a qualidade da ração fornecida. O presente experimento baseia-se em diferentes níveis quantitativos de alimento, segundo teoria de que uma menor ingestão de energia melhora a conversão alimentar, diminui a gordura da carcaça e aumenta a duração do período de engorda (BELLAVER, 1992).
A diminuição da gordura e o aumento da carne na carcaça significa melhor classificação desta, que obtém, por consequência, melhor preço a nível de indústria. Por outro lado, o aumento da duração do período de engorda resultante dos menores ganhos de peso, implica em maior custo do uso das instalações, embora permita alterar a data de abate dos animais de 
acordo com a flutuação do mercado.

A garantia do fornecimento dos nutrientes necessários à dieta, um ajuste semanal das quantidades fornecidas e a não existência de competição animal no consumo restringido são pontos básicos a observar para o sucesso de um programa de racionamento em suínos.

Este experimento teve por objetivo avaliar o efeito de diferentes níveis de restrição alimentar quantitativa sobre desempenho e características de carcaça de leitões em terminação.

\section{Material e Métodos}

O experimento foi desenvolvido na granja de suínos da Fazenda Experimental do Cangüiri, da Universidade Federal do Paraná, no período de junho a outubro de 1998. Foram utilizados 62 animais mestiços Landrace x Large White, distribuídos em 31 boxes, alocando-se um casal por box. O experimento compreendeu a fase de terminação até o abate, com pesagens semanais, sendo que o peso médio inicial foi de $79,97 \pm 2,99 \mathrm{~kg}$ e o peso médio final de abate de $96,37 \pm 4,01 \mathrm{~kg}$.

Tabela 2. Médias ajustadas e desvios-padrão das características de desempenho: conversão alimentar (CA), peso final (PF), ganho de peso diário (GPD), consumo diário (CON).

\begin{tabular}{|c|c|c|c|c|c|}
\hline \multirow[b]{2}{*}{ Característica } & \multicolumn{4}{|c|}{ Grau de restrição alimentar } & \multirow[b]{2}{*}{ MÉDIA } \\
\hline & $0 \%$ & $7 \%$ & $14 \%$ & $21 \%$ & \\
\hline $\mathrm{CA}$ & $3,74 \pm 0,68$ & $3,88 \pm 0,52$ & $3,92 \pm 0,42$ & $3,82 \pm 0,49$ & $3,84 \pm 0,51$ \\
\hline PF (kg) & $98,52 \pm 5,87$ & $95,47 \pm 3,83$ & $95,61 \pm 2,72$ & $96,15 \pm 3,31$ & $96,37 \pm 4,01$ \\
\hline GPD (kg) & $0,83 \pm 0,19$ & $0,71 \pm 0,06$ & $0,68 \pm 0,08$ & $0,65 \pm 0,08$ & $0,71 \pm 0,13$ \\
\hline $\mathrm{CON}(\mathrm{kg})$ & $3,00 \pm 0,12$ & $2,73 \pm 0,28$ & $2,62 \pm 0,00$ & $2,45 \pm 0,14$ & $2,69 \pm 0,26$ \\
\hline
\end{tabular}

Os tratamentos compreenderam quatro níveis de arraçoamento: à vontade (T1), 7 \% (T2), $14 \%$ (T3) e $21 \%$ de restrição em relação ao consumo à vontade (T4). A dieta foi à base de milho e farelo de soja (Tabela 1), formulada de acordo com as recomendações de ANDRIGUETTO et al. (1996).

Os animais foram abatidos e submetidos à avaliação de carcaça, segundo as normas do Método Brasileiro de Classificação de Carcaças (ABCS, 1973). A leitura da área de olho de lombo foi feita através de Planímetro Eletrônico (HAYASHI DENKOH Co., LTD - AAC - 400), usando-se a média de três leituras para cada desenho do olho de lombo.

Os resultados foram submetidos à análise de variância e análise de regressão. Para as características de carcaça, foi utilizado um arranjo fatorial 2X4 (sexo $\mathrm{x}$ nível de restrição). Para medidas de desempenho animal, o peso Inicial foi usado como covariável. Para as medidas de carcaça foram usadas como covariáveis o peso final e idade de abate. Como não houve interação sexo x nível de restrição para nenhuma característica, a análise de regressão foi efetuada apenas para a média dos sexos.

\section{Resultados e Discussão}

As médias dos dados de desempenho são apresentados na Tabela 2, e os das características de carcaça na Tabela 3. Os resultados das análises de regressão dessas características estão na Tabela 4.

Tabela 3. Médias ajustadas e desvios-padrão das características de carcaça: peso de carcaça fria (PC), rendimento de carcaça (RC), espessura de toucinho média (ETM), peso do pernil (PP), porcentagem de pernil (PP\%), área de olho de lombo (AOL) e relação carne:gordura (RCG).

\begin{tabular}{|c|c|c|c|c|c|}
\hline \multirow[b]{2}{*}{ Característica } & \multicolumn{4}{|c|}{ Grau de restrição alimentar } & \multirow[b]{2}{*}{ MÉDIA } \\
\hline & $0 \%$ & $7 \%$ & $14 \%$ & $21 \%$ & \\
\hline $\mathrm{PC}(\mathrm{kg})$ & $80,8 \pm 6,90$ & $75,12 \pm 3,96$ & $75,71 \pm 5,42$ & $75,79 \pm 3,82$ & $76,73 \pm 5,46$ \\
\hline $\mathrm{RC}(\%)$ & $82,05 \pm 1,23$ & $77,79 \pm 5,74$ & $79,89 \pm 5,98$ & $79,64 \pm 5,30$ & $79,77 \pm 5,13$ \\
\hline ETM $(\mathrm{cm})$ & $3,32 \pm 0,48$ & $2,91 \pm 0,52$ & $2,85 \pm 0,51$ & $2,87 \pm 0,46$ & $2,98 \pm 0,52$ \\
\hline $\mathrm{PP}(\mathrm{kg})$ & $11,11 \pm 1,45$ & $10,90 \pm 0,75$ & $11,34 \pm 0,99$ & $11,14 \pm 0,94$ & $11,12 \pm 1,04$ \\
\hline $\mathrm{PP} \%$ & $27,43 \pm 1,73$ & $29,04 \pm 1,64$ & $29,97 \pm 1,79$ & $29,40 \pm 2,06$ & $29,00 \pm 1,99$ \\
\hline $\operatorname{AOL}\left(\mathrm{cm}^{2}\right)$ & $31,18 \pm 3,09$ & $30,34 \pm 4,87$ & $32,57 \pm 6,18$ & $30,74 \pm 4,12$ & $31,21 \pm 4,71$ \\
\hline RCG & $0,76 \pm 0,20$ & $0,72 \pm 0,17$ & $0,71 \pm 0,19$ & $0,66 \pm 0,16$ & $0,71 \pm 0,18$ \\
\hline
\end{tabular}

A restrição alimentar reduziu linearmente $(\mathrm{p}<0,05)$ o consumo e o ganho de peso diário, resultando em um aumento linear $(\mathrm{p}<0,05)$ no tempo para os animais atingirem idade de abate (ajustado para $100 \mathrm{~kg}$ ). Não se observou, porém, efeito significativo sobre a conversão alimentar, embora houvesse diminuição linear $(p<0,05)$ na espessura média de toucinho e aumento linear $(\mathrm{p}<0,05)$ na porcentagem de pernil (Tabelas 2, 3 e 4). O peso e o rendimento de carcaça foram 
Restrição Alimentar em Suínos em Terminação

afetados de forma quadrática $(\mathrm{p}<0,05)$, enquanto o comprimento da carcaça não foi afetado $(p>0,05)$. A área de olho de lombo e a relação carne:gordura não diferiram significativamente entre os níveis de arraçoamento $(\mathrm{p}>0,05)$.

Tabela 4. Resultados da análise de regressão para as variáveis ganho de peso diário (GPD), consumo diário (CON), peso de carcaça fria (PC), rendimento de carcaça (RC), espessura de toicinho média (ETM), percentagem de pernil (PP\%) e idade de abate ajustada $\mathrm{p} / 100 \mathrm{~kg}$ (IDaj).

\begin{tabular}{|c|c|c|c|c|}
\hline Variável & Regressão $^{1}$ & $\mathrm{R}^{2}$ & Probabilidade & C.V. $(\%)^{2}$ \\
\hline GPD (kg) & $-0,008 X+0,799$ & 0,90 & 0,003 & 15,74 \\
\hline CON (kg) & $-0,025 X+2,961$ & 0,96 & $<0,001$ & 6,32 \\
\hline $\mathrm{PC}(\mathrm{kg})$ & $0,089 X^{2}-0,823 X+80,462$ & 0,76 & 0,029 & 5,50 \\
\hline $\mathrm{RC}(\mathrm{kg})$ & $0,020 X^{2}-0,502 X+81,615$ & 0,75 & 0,035 & 5,44 \\
\hline $\operatorname{ETM}(\mathrm{cm})$ & $0,020 \mathrm{X}+3,201$ & 0,72 & 0,015 & 14,46 \\
\hline PP (\%) & $0,098 X+27,933$ & 0,68 & 0,005 & 6,50 \\
\hline IDaj $(p / 100 \mathrm{~kg})$ & $0,359 X+172,70$ & 0,70 & 0,011 & 3,41 \\
\hline
\end{tabular}

${ }^{1} \mathrm{X}$ é o nível de restrição alimentar. ${ }^{2}$ Coeficiente de variação da análise de variância.

Verificou-se um efeito semelhante da restrição quantitativa de alimento sobre machos e fêmeas, embora estas depositaram menos gordura e apresentaram melhor relação carne:gordura em todos os níveis de restrição, evidenciando melhor qualidade de carcaça.

Considerando que nas condições em que foi desenvolvido o presente experimento, pode ser concluído que o efeito da restrição alimentar quantitativa até o nível de $21 \%$ em relação ao consumo à vontade afetou de forma semelhante machos castrados e fêmeas, embora as fêmeas depositassem menos gordura em todos os níveis; houve diminuição linear do ganho de peso e aumento da idade de abate, sem afetar a conversão alimentar. Por outro lado, a restrição alimentar afetou de forma significativa todas as características que estimam a deposição de gordura na carcaça, demonstrando melhores resultados com restrição na ordem de $14 \%$ do consumo à vontade.

\section{REFERÊNCIAS BIBLIOGRÁFICAS}

ANDRIGUETTO, J.M.; PERLY, L.; MINARDI, I.; FLEMMING, J.S.; VINNE, J.U. van der; FLEMMING, R.; SOUZA, G.A. de; ANDRIGUETTO, J.L.; DUTRA, M.J.; STEIFERT, C.R. Normas $e$ Padrões de Nutrição e Alimentação Animal. Revisão 1996, DTPA-SDR-MAARA, Curitiba, 1996. 145p.

ASSOCIAÇÃO BRASILEIRA DE CRIADORES DE SUÍNOS. Método Brasileiro de Classificação de Carcaças. Estrela: Conselho Técnico da ABCS, 1973. 17p. (Publicação Técnica n.2).

BELLAVER, C. Restrição da alimentação para suínos em terminação. Suinocultura Dinâmica, n.2, 1992.

GODFREY, N.W.; FRAPPLE, P.G. ; PATERSON, ${ }^{\mathrm{a}}$ M.; PAYNE, H.G. Differences in the composition and tissue distribuition of pig carcasses due to selection and feeding level. Anim. Prod., 53:97-103. 1991.

LAWRENCE, A.B.; APPLEBY, M.C.; MACLEOD, H.A. Measuring hunger in the pig using operant conditioning: the effect of food restriction. Anim. Prod., 47:131-137. 1988. 